\title{
Inconstitucionalidade circunstancial e a Ação Direta de Inconstitucionalidade n.4.068
}

\author{
Circumstancial unconstitutionality and the Direct Action of Unconstitutionality n. 4.068
}

Inconstitucionalidad circunstancial y la Acción Directa de Inconstitucionalidad 4.068

Recebido: 01/03/2021 | Revisado: 03/03/2021 | Aceito: 11/03/2021 | Publicado: 18/03/2021

\author{
Raquel Lauriano Rodrigues Fink \\ ORCID: https://orcid.org/0000-0002-0245-6349 \\ Universidade Paranaense, Brasil \\ E-mail: raquellauriano@hotmail.com \\ Felipe Cazuo Azuma \\ ORCID: https://orcid.org/0000-0001-9379-4740 \\ Universidade Paranaense, Brasil \\ E-mail: felipe.azuma@gmail.com \\ Celso Hiroshi Iocohama \\ ORCID: https://orcid.org/0000-0002-0686-0330 \\ Universidade Paranaense, Brasil \\ E-mail: celso@prof.unipar.br
}

\begin{abstract}
Resumo
A tese da inconstitucionalidade circunstancial apresentada na Ação Direta de Inconstitucionalidade n. 4.068/DF significou a possibilidade de uma nova forma de controle de constitucionalidade. O trabalho visou a viabilidade da declaração de inconstitucionalidade momentânea em decorrência de circunstâncias fáticas excepcionais e não propriamente do conteúdo da norma. Para tanto, procedeu-se o exame da teoria da inconstitucionalidade circunstancial e seus fundamentos abordando as críticas direcionadas à nova tese. A discussão envolve a teoria suscitada na Ação Direita de Inconstitucionalidade promovida pelo Conselho Federal da Ordem dos Advogados do Brasil (CFOAB) que tem por objeto o $\S 1^{\circ}$ do art. 16 da Lei n. 11.457/07. A ação sustenta que inobstante a inconstitucionalidade circunstancial do dispositivo impugnado, referida lei merece ser preservada. Para a pesquisa utilizou-se o método analítico-descritivo, pesquisa bibliográfica a artigos científicos, livros e jurisprudência. O estudo conclui que a decisão do Supremo Tribunal Federal não enfrentou a tese da inconstitucionalidade circunstancial, sob o fundamento de que implicaria em invadir a discricionariedade do administrador para analisar a infraestrutura do órgão envolvido e sua compatibilidade com as condições e o prazo de aplicação da norma questionada, em violação ao princípio da separação dos poderes.

Palavras-chave: Inconstitucionalidade circunstancial; Controle de constitucionalidade; Jurisprudência de crise; Ação direta de inconstitucionalidade.
\end{abstract}

\begin{abstract}
The circumstantial unconstitutionality thesis presented in the Direct Action of Unconstitutionality n. 4068 / DF meant the possibility of a new form of constitutionality control. The theme is part of the analysis of the feasibility of declaring momentary unconstitutionality due to exceptional factual circumstances and not exactly the content of the standard. Therefore, the circumstantial unconstitutionality and its foundations was examined, addressing the criticisms directed at the new thesis. The discussion involves the thesis raised in the Direct Action of Unconstitutionality promoted by the Federal Council of the Brazilian Lawyers (CFOAB). The process refers that despite the circumstantial unconstitutionality of the contested norm that law deserves to be preserved. For the research it was uses the analyticaldescriptive method, bibliographic research to scientific articles, books and Jurisprudence. Finally concludes the decision of the Federal Supreme Court did not faced the thesis of circumstantial unconstitutionality, because it would imply invading the discretion of the administrator implying in violation of the principle of separations of powers.

Keywords: Circumstantial unconstitutionality; Constitutionality control; Crisis Jurisprudency; Direct action of unconstitutionality.

\section{Resumen}

La tesis de inconstitucionalidad circunstancial presentada en la Acción Directa de Inconstitucionalidad n. 4.068 / DF significó la posibilidad de una nueva forma de control de constitucionalidad. El trabajo tuvo como objetivo la viabilidad de declarar la inconstitucionalidad momentánea por circunstancias fácticas excepcionales y no exactamente el contenido de la norma. Por tanto, se examinó la teoría de la inconstitucionalidad circunstancial y sus fundamentos, atendiendo las críticas dirigidas a la nueva tesis. La discusión involucra la teoría planteada en la Acción de Directa de Inconstitucionalidad promovida por el Consejo Federal del Colegio de Abogados de Brasil (CFOAB) cuyo objeto es el $\S 1$ del art. 16 de la Ley núm. 11.457/07. La demanda alega que a pesar de la inconstitucionalidad circunstancial de la disposición impugnada, dicha ley merece ser preservada. Para la investigación se utilizó el método analítico-descriptivo,
\end{abstract}


investigación bibliográfica hasta artículos científicos, libros y jurisprudencia. El estudio concluye que la decisión del Supremo Tribunal Federal no abordó la tesis de inconstitucionalidad circunstancial, por considerar que implicaría invadir la discreción del administrador para analizar la infraestructura del órgano involucrado y su compatibilidad con las condiciones y plazo de vigencia. aplicación de la norma cuestionada, en violación del principio de separación de poderes.

Palabras clave: Inconstitucionalidad circunstancial; Control de constitucionalidad; Jurisprudencia de crisis; Acción directa de inconstitucionalidad.

\section{Introdução}

$\mathrm{O}$ artigo tem por finalidade trazer apontamentos sobre a denominada (in)constitucionalidade circunstancial e, sob este foco, analisar a Ação Direta de Inconstitucionalidade n. 4.068/DF.

Com a pandemia de COVID-19, o mundo viu-se afetado, sob todos os aspectos, não só da saúde pública. A indústria, o comércio, a política foram afetados. E como não poderia deixar de ser, o Direito também não permaneceu ileso ao novo coronavírus. Uma situação excepcional instaurou-se. Assim, a interpretação constitucional sobre determinados atos normativos expedidos neste período, também passou a ser objeto de questionamento, notadamente, se a rigidez de interpretação constitucional deve ser a mesma neste período ou poderia ser flexibilizada.

Buscou-se estudar a tese da inconstitucionalidade circunstancial, ponderando a existência da jurisprudência da crise. Sobre o primeiro espectro deste artigo - da inconstitucionalidade circunstancial -, a problematização remete à possibilidade de leis ou atos normativos serem considerados (in)constitucionais por um certo lapso temporal, em razão de alguma circunstância excepcional, retomando sua condição original após cessada a situação de excepcionalidade. Pretendeu-se esclarecer como e quais os fundamentos desta nova teoria, ponderando as críticas à esta.

Em momento posterior ver-se-á que a questão da chamada inconstitucionalidade circunstancial foi objeto de análise perante o Supremo Tribunal Federal na ADI 4.068, a respeito da qual foram explicitados os fundamentos de aplicação da citada tese ao caso em concreto e, finalmente, crítica à decisão da Ação Direta de Inconstitucionalidade pelo Supremo Tribunal Federal.

Como objetivo, o artigo visou analisar a viabilidade da declaração de inconstitucionalidade momentânea apontada na Ação Direita de Inconstitucionalidade n. 4.068/DF promovida pelo Conselho Federal da Ordem dos Advogados do Brasil (CFOAB) cunhada de "inconstitucionalidade circunstancial" abordando seus fundamentos, as críticas, bem como o entendimento dado pelo Supremo Tribunal Federal à nova tese no julgamento da referida ação.

\section{Metodologia}

Para a pesquisa utilizou-se o método analítico-descritivo na abordagem dos temas relacionados ao objeto do estudo, bem como a pesquisa bibliográfica a artigos científicos, livros e jurisprudência.

A pesquisa bibliográfica, portanto, está inserida na documental assim classificada pelos pesquisadores que estudam a metodologia da pesquisa jurídica a exemplo de Adeodato (1988, p. 175) ao afirmar que "no caso da pesquisa jurídica, é importante o estudo de documentos como: leis; repertórios de jurisprudência; sentenças; contratos; anais legislativos; pareceres etc., constituindo uma vertente específica da pesquisa bibliográfica que podemos chamar de documental".

Importante ressaltar que de acordo com Cervo e Bervian (2003) a pesquisa científica pode adotar várias formas.

\section{Resultados e Discussão}

\subsection{Considerações sobre a teoria e seus fundamentos}

Antes da pandemia, Barcellos $(2005$, pp. 231,232) já tratava sobre a inconstitucionalidade circunstancial da seguinte maneira 
Trata-se da declaração de inconstitucionalidade da norma produzida pela incidência da regra sobre uma determinada situação específica. [...]

É possível cogitar de situações nas quais um enunciado normativo, válido em tese e na maior parte de suas incidências, ao ser confrontado com determinadas circunstâncias concretas, produz uma norma inconstitucional. Lembre-se que, em função da complexidade dos efeitos que se pretendem produzir e/ou da multiplicidade de circunstâncias de fato sobre as quais incidem, também as regras podem justificar diferentes condutas que, por sua vez, vão dar conteúdo a normas diversas. Cada uma dessas normas opera em um ambiente fático próprio e poderá ser confrontada com um conjunto específico de outras incidências normativas, justificadas por enunciados diversos. Por isso, não é de estranhar que determinadas normas possam ser inconstitucionais em função desse seu contexto particular, a despeito da validade geral do enunciado do qual derivam. [grifo do autor]

É certo que depois de 2020, este tema ganhou contornos especiais, em razão das circunstâncias excepcionais que encobriram o mundo desde o início do ano decorrente da pandemia do coronavírus.

Por conta disso, governantes em todo o globo tiveram que adotar medidas e decisões urgentes visando a contenção da pandemia e a redução de seus danos. Talvez o principal dilema posto foi(é) o da questão das liberdades civis, frente às medidas implementadas que restringem até mesmo a liberdade de ir e vir.

Por evidente que em situações de normalidade estas medidas não seriam aceitáveis, nem mesmo consideradas por autoridades e governos (Freire, Frazão, Mudrovitsch \& Rufino, 2020) e, caso fossem, certamente não resistiriam ante qualquer Corte Constitucional, sob a égide de uma Constituição minimamente democrática.

Todavia, em razão da excepcionalidade vivida, já se preferiu até mesmo falar sobre "jurisprudência de crise" (Mendes, 2020), ou seja, de uma jurisprudência específica para uma determinada situação ou época.

Para Pinheiro (2014, p.170) “a ‘jurisprudência da crise’ traduz um 'processo negocial' entre a interpretação normativa da Constituição e a necessidade de ceder perante as “exigências das circunstâncias”. Neste sentido explica Padilha (2020, p.207) que "Existem hipóteses em que, embora a norma seja constitucional, se aplicada em determinadas circunstâncias, situações específicas, poderia ser considerada inconstitucional".

Está-se diante, então, da pretensão de reconhecimento de uma (in)constitucionalidade momentânea que decorreria mais das circunstâncias fáticas excepcionais do que propriamente do conteúdo da norma.

Referida técnica serve tanto para a declaração de constitucionalidade quanto de inconstitucionalidade. A declaração de constitucionalidade seria, de regra, para normas editadas no período de excepcionalidade que, porventura, conflitassem com a Constituição. Já a declaração de inconstitucionalidade serviria para normas editadas no período de normalidade, mas que ante a situação excepcional tornar-se-iam momentaneamente inconstitucionais.

Ponderam Chaves e Arcaro (2020) que "Diante desta técnica de controle de constitucionalidade tem-se a declaração de inconstitucionalidade sem a pronúncia da nulidade, reconhecendo-se sua inconstitucionalidade circunstancial até que se implementem as condições fáticas que viabilizem a congruência da norma com o texto constitucional”.

Aqui cabe um parêntese: o texto do Min. Gilmar Mendes - "Jurisprudência de Crise e Pensamento do Possível: caminhos constitucionais", sobre o qual são feitos apontamentos neste tópico trata, dentro do contexto da pandemia, do reconhecimento de situações de constitucionalidade.

De acordo com Mendes (2020), a atuação do STF em um contexto de crise "demanda uma abertura hermenêutica da jurisdição constitucional à compreensão e conformação da realidade econômica e social experimentada". Em outras linhas, significa dizer que o STF não pode, em tempos de crise, ser um tribunal hermeticamente fechado aos acontecimentos e mudanças sociais abruptas ocasionadas pela pandemia.

Em situações como a presente a Administração Pública precisa agir rapidamente o que pode conduzir a ações questionáveis do ponto de vista da Constituição Federal. Diante deste quadro complexo, Mendes (2020) chega a afirmar que “parece evidente que as normas jurídicas soam, em um ponto de vista estritamente pragmático, um mero detalhe no debate sobre 
a aprovação de medidas essenciais”. Deve-se, portanto, prezar pela compatibilização de aparentes contradições e abertura à busca por alternativas menos herméticas, sob o ponto de vista legal.

Neste aspecto, válido o ensino de Häberle (2002, p. 24) que concebe o Direito Constitucional como disciplina diretamente vinculada à cultura, à filosofia e à realidade contemporânea e entende que todas as situações relacionadas ao tex to constitucional não podem ser interpretadas de modo isolado reforçando-se, assim, a teoria ora em comento.

Gilmar Mendes (2020) refere que as normas jurídicas, notadamente a Constituição Federal, devem ser vistas como meio necessário à solução de situações de crise devendo ser afastadas aparentes contradições normativas. Referido autor afirma que esta questão tem sido debatida na seara constitucionalista, mencionando que Gustavo Zagrebelsky (1999) já tratou sobre o ethos da Constituição na sociedade moderna.

De acordo com Zagrebelsky (1999, p. 13 como citado em Mendes 2020) é relevante a busca pela proteção dos princípios ainda que, teoricamente, se esteja diante de valores em contradição. Referido professor italiano, ressalta a importância de uma “concordância prática" que se efetiva não por meio da "simples amputação de potencialidades constitucionais, senão principalmente mediante soluções acumulativas, combinatórias, compensatórias, que conduzam os princípios constitucionais a um desenvolvimento conjunto e não a um declínio conjunto”.

Conclui o autor que o pensamento a ser adotado em sede constitucional deve ser o "pensamento do possível", entendimento adotado também por Peter Härbele (2002).

Esta técnica de decisão supera o modelo binário entre constitucionalidade e inconstitucionalidade. Para sua adoção, de certa forma, o intérprete deve aderir a teoria da anulabilidade para a qual a norma em questão deve ser considerada constitucional até que um órgão competente decida pela sua inconstitucionalidade (Freire et al., 2020).

Apesar de a regra no Direito brasileiro ser a da nulidade, a jurisprudência do STF com base na legislação ${ }^{1}$ reconhece a necessidade de se modular os efeitos da declaração de inconstitucionalidade, relativizando a teoria da nulidade.

O cerne desta teoria parece ser justamente o fato de que as Cortes Constitucionais têm o papel, para além de retirar dos sistemas jurídicos normas inconstitucionais, de preservar a legislação produzida, cuja inconstitucionalidade seja momentânea superando-se, assim, o modelo binário entre constitucionalidade e inconstitucionalidade.

Roberta Simões Nascimento (2020) elucida como seria o ciclo temporário de inconstitucionalidade do seguinte modo: "Lei " $X$ " constitucional $\rightarrow$ início excepcionalidade "Y" $\rightarrow$ Lei "X" inconstitucional $\rightarrow$ término excepcionalidade "Y" $\rightarrow$ Lei "X" constitucional."

Analisados os fundamentos da teoria/técnica da inconstitucionalidade circunstancial, no próximo item serão analisadas as críticas à aplicação desta teoria.

\subsection{Críticas à teoria}

Para os críticos da teoria tem-se que é duvidoso que o sistema de controle de constitucionalidade brasileiro comporte essa via, mesmo de acordo com o art. 27 da Lei n. 9.868/99, o qual prevê que o Supremo Tribunal Federal pode restringir os efeitos da declaração de inconstitucionalidade.

Da mesma forma, com outras técnicas de interpretação consideradas intermediárias, como a interpretação conforme, declaração de nulidade sem redução de texto, nelas se concebem uma lei como estando em concordância ou não com a Constituição. Portanto, nestes casos a inconstitucionalidade não depende de circunstâncias momentâneas experimentadas, mas decorrerá somente de sua incompatibilidade (ou não) com a Constituição.

\footnotetext{
${ }^{1}$ Cf. Art. 27 da Lei no $9.868 / 1999$ e art. 11 da Lei no 9.882/1999.
} 
Outra crítica que se faz à esta teoria é a seguinte: “após a superação da situação anormal, como explicar a retomada da validade da norma declarada inconstitucional?" [grifo do autor], (Bernardes, 2020). Ora, como o Congresso Nacional não pode repristinar uma lei, a pretensão de dar poder à Corte de declarar que uma norma é inconstitucional até que cesse o estado de excepcionalidade, seria atribuir ao Supremo um poder que nem o Congresso tem.

Ainda, a "lógica do controle de constitucionalidade não comporta decisões de mérito com vigência temporária" (Nascimento, 2020) e, cabe ao legislativo editar leis temporárias de acordo com o estatuído no artigo art. $2^{\circ}$ da Lei de Introdução às Normas do Direito Brasileiro. Estar-se-ia criando um novo instituto: o da inconstitucionalidade temporária.

Talvez o grande problema da adoção desta teoria/técnica encontra-se na questão do marco temporal e sensorial da situação de excepcionalidade. Há de se questionar, portanto, quem delimita o que é uma situação excepcional, quem determina até quando esta situação de anormalidade pode perdurar e quais seus termos a quo e ad quem.

A incerteza quanto aos questionamentos acima pode levar à insegurança jurídica. Pior, pode conduzir à paradoxal perpetuação de situações excepcionais.

Considerados os pressupostos da nova tese, no tópico seguinte será analisada a ADI n. 4.068/DF na qual, ainda fora do contexto atual da pandemia, o Supremo Tribunal Federal abordou a temática.

\subsection{Inconstitucionalidade circunstancial e a ADI 4.068/DF}

A tese da inconstitucionalidade circunstancial foi desenvolvida na Ação Direta de Inconstitucionalidade (ADI 4.068/DF) proposta pelo Conselho Federal da Ordem dos Advogados do Brasil - CFOAB, subscrita por seu então Presidente (Cesar Britto) e pelo advogado Francisco Resek.

A ação, incialmente distribuída por prevenção ao Ministro Celso de Mello (que se declarou suspeito com base na norma inscrita no art. 135, parágrafo único, do CPC de 1973) foi redistribuída à relatoria da Ministra Carmem Lúcia.

A Ação Direta de Inconstitucionalidade (2008) tem por objeto o $§ 1^{\circ}$ do art. 16 da Lei n. 11.457/07 que, nos termos da petição inicial, "fixa o dia $1^{\circ}$ de abril de 2008 como termo para a transferência integral do acervo da dívida ativa do INSS e do FNDE para a União e, por conseguinte, para a Procuradoria-Geral da Fazenda Nacional", tratando da segunda fase de implantação da denominada "Super-Receita".

Inobstante as diversas formas de declaração de inconstitucionalidade de uma lei ou ato normativo, o Conselho Federal da Ordem dos Advogados do Brasil construiu uma nova tese que poderia ensejar a ampliação das modalidades e o estudo do controle de constitucionalidade no Direito nacional. Refere-se, como já mencionado, à tese da "inconstitucionalidade circunstancial" e a declaração de uma lei “ainda inconstitucional” (Coelho, 2014).

Com vistas à explanação da tese serão abordados os fundamentos apresentados pelo Conselho requerente na petição inicial, os argumentos aduzidos nas manifestações das demais partes do processo, bem como as decisões judiciais proferidas na ação.

A Ação Direta de Inconstitucionalidade n. 4.068 foi proposta em 14/04/2008 com pedido de medida cautelar. Adotando o rito do art. 12 da Lei n. 9.868/99 a Relatora determinou fossem solicitadas informações da autoridade apontada como coatora para prestar informações e, na sequência, vistas ao Advogado-Geral da União e ao Procurador-Geral da República, sucessivamente, para apresentação de suas manifestações.

De início, necessário destacar a norma impugnada na ação, qual seja, o art. 16, § 1º da Lei n. 11.457/2007

Art. 16. A partir do $1^{\circ}$ (primeiro) dia do $2^{\circ}$ (segundo) mês subsequente ao da publicação desta Lei, o débito original e seus acréscimos legais, além de outras multas previstas em lei, relativos às contribuições de que tratam os arts. $2^{\circ}$ e $3^{\circ}$ desta Lei, constituem dívida ativa da União. 
$\S 1^{\circ} \mathrm{A}$ partir do $1^{\circ}$ (primeiro) dia do $13^{\circ}$ (décimo terceiros) mês subsequente ao da publicação desta Lei, o disposto no caput deste artigo se estende à dívida ativa do Instituto Nacional do Seguro Social - INSS e do Fundo Nacional de Desenvolvimento da Educação - FNDE decorrente das contribuições a que se referem os arts. $2^{\circ}$ e $3^{\circ}$ desta Lei.

Nos termos da petição inicial, a referida lei criou a chamada "Super-Receita" e dividiu sua implantação em duas etapas, sendo que a "fase I" (prevista no caput do art. 16) implicou na transferência para a União e, consequentemente, para a Procuradoria-Geral da Fazenda Nacional (PGFN), dos créditos tributários constituídos, porém não inscritos em dívida ativa do INSS e do FNDE. A segunda fase ("fase II"), objeto de impugnação na ADI, está prevista no $\S 1^{\circ}$ do mesmo artigo, conforme trecho da peça de ingresso

compreende a transferência de todo o acervo da dívida ativa, incluindo o sistema informatizado de controle dos créditos tributários nela inscritos, os processos administrativos a estes referentes, os dossiês ou processos administrativos de acompanhamento de processos judiciais deles decorrentes, e os processos judiciais em que se discutam esses créditos. (ADI 4068, 2008)

Segundo narrativa do Conselho requerente "A PGFN opera já há algum tempo com absoluta sobrecarga de atividades, além de infraestrutura precária e carência de recursos humanos e materiais" (ADI, 2008, p. 5). Aduz que, muito embora o Tribunal de Contas da União - TCU já tivesse apontado, em 2003, a carência de recursos humanos e o volume exacerbado de trabalho dos Procuradores da Fazenda Nacional, a União não proveu as necessidades estruturais da PGFN que, a contrassenso, acabou por receber mais atribuições.

Registra o CFOAB, no entanto, que não se trata de repúdio à lei que, segundo afirma, "representou um inegável avanço na organização da Administração Fazendária". Entretanto, afirma que a criação de 1.200 cargos e seccionais não estava relacionada apenas às novas atribuições legadas à Procuradora-Geral da Fazenda Nacional, mas em imprimir esforços para que o órgão pudesse acompanhar a expansão do Poder Judiciário e das ações promovidas pela União.

Deste modo, como expõe o Conselho Federal, nota-se que apesar da previsão legislativa de criação de cargos da carreira de Procurador da Fazenda Nacional e administrativos, bem como instalação das seccionais da PGFN, ainda assim não havia uma estrutura institucional mínima apta a absorver a demanda dos processos advindos da Procuradoria Geral Federal comprometendo a representação judicial da União.

Como mencionado, a transferência de atribuições administrativas foi programada para duas fases previstas no art. 16 da Lei n. 11.457/07, sendo a "fase I" (art. 16, caput) - transferência de créditos tributários previdenciários não inscritos em dívida ativa, e a "fase II" (art. 16, $\S 1^{\circ}$ ) - com a transferência de todos os créditos tributários inscritos em dívida ativa do INSS e do FDNE.

O CFOAB aduz que o art. 16 teria eficácia parcial, à época, pois promover-se-ia a implementação da "fase II" sem que houvesse a instalação da estrutura mínima na PGFN, pois o Poder Público não teria adotado as medidas necessárias à estruturação do órgão no período de vacatio legis a possibilitar o recebimento das novas atribuições. Afirma que "A inércia do Administrador rendeu à norma sua inconstitucionalidade circunstancial, pois sem o provimento dos cargos previstos, a PGFN estaria “circunstancialmente incapacitada de realizar o seu ofício constitucional” (ADI 4.068, 2008, fl. 20). [grifo do autor]

Para o CFOAB, a ação funda-se na impossibilidade administrativa de a PGFN assumir o acréscimo de trabalho decorrente da criação da Super-Receita, razão pela qual o dispositivo impugnado deveria ser declarado circunstancialmente inconstitucional até que a Procuradoria-Geral da Fazenda Nacional tivesse estrutura mínima necessária a realizar o encargo a que foi sujeitada pela lei. Ainda, defende que a constitucionalidade da norma está condicionada à implementação de condições mínimas a autorizar a sua eficácia, quais sejam: provimento de 1.200 cargos de Procurador da Fazenda Nacional (art. 18 da Lei 
11.457/07); instalação de 120 seccionais da PGFN (art.19 da lei) e publicação de lei que tratasse dos cargos, da lotação, da remuneração, do exercício e da situação funcional dos servidores oriundos do Ministério da Previdência Social.

Assim, carece pontuar os fundamentos que sustentam a alegação de inconstitucionalidade circunstancial do dispositivo impugnado.

O CFOAB ponderou que a implementação da "fase II" representa uma contradição em relação ao objetivo da criação da Super-Receita, já que a PGFN não tem condições estruturais mínimas a suportar as novas atribuições que lhe foram impostas.

De outro lado, o Conselho ressalta a relevância da Lei em comento que criou a Super-Receita e aperfeiçoou a Administração Tributária afirmando que, inobstante a inconstitucionalidade circunstancial do dispositivo impugnado a lei deveria ser preservada.

Portanto, a ação busca uma decisão judicial que, par além de sanar o vício de inconstitucionalidade também preserve a norma. E para justificar uma decisão neste sentido, o requerente suscita as novas técnicas de decisão adotadas pelo Supremo Tribunal Federal no controle de constitucionalidade tecendo comparações com a tese apresentada pelo Conselho requerente.

Ao que se vê, a tese da inconstitucionalidade circunstancial apresentada pelo CFOAB permite solução semelhante a outras já proferidas pelo Supremo Tribunal Federal em que se declarou "ainda constitucional” norma tida por inconstitucional, face a "circunstâncias fáticas subjacentes" e da "declaração de inconstitucionalidade sem pronúncia de nulidade” (ADI 4.068, 2008, p. 24).

Finalizando, o Conselho sustentou que o dispositivo impugnado deve ser declarado circunstancialmente inconstitucional por violação aos princípios do Estado de Direito e do devido processo legal face a inobservância do "postulado normativo aplicativo da razoabilidade como congruência”, além de violar o princípio da continuidade dos serviços públicos e o princípio da eficiência administrativa (ADI 4.068, 2008, p.36-42). Em sede cautelar o Conselho Federal requereu a suspensão da eficácia do art. 16, § $1^{\text {o }}$, da Lei 11.457/07 até julgamento da ação.

Quanto ao mérito, requereu a procedência da ação

mediante declaração de inconstitucionalidade sem a pronúncia da nulidade do art. 16, $\S 1^{\circ}$, da Lei 11.457/07, reconhecendo-se sua inconstitucionalidade circunstancial até que se implementem as condições fáticas que viabilizem a transferência total à PGFN das atribuições hoje incumbentes à PGF, condições essa (SIC) que são, expressamente: b.1) a posse e a entrada em exercício do número de procuradores faltantes para completar a dotação legal prevista no art. 18 dessa mesma Lei e a publicação da lei, tratando dos cargos, da lotação, da remuneração, do exercício e da situação funcional dos servidores oriundos do Ministério da Previdência Social, . . . ou, sucessivamente,

b.2) a posse e a entrada em exercício do número de procuradores faltantes para completar a dotação legal prevista no art.18 dessa mesma Lei e a instalação das 120 seccionais previstas no art. 19 também dessa Lei. (ADI 4.068, 2008, p. 45). [grifo do autor]

O Presidente da República prestou informações aduzindo que a Lei 11.457/07 representa o atendimento ao princípio da eficiência e que decisões judiciais que possam interferir nas atividades da Administração Pública devem ser encaradas como medidas de exceção, sob pena de violação ao princípio da separação dos poderes.

O Congresso Nacional apresentou informações asseverando que a lei não condicionou a aplicação do art. 16 a qualquer medida administrativa e que a própria lei tratou da questão atinente à estrutura administrativa para implementação da SuperReceita.

Por sua vez, o Advogado-Geral da União afirmou que "não houve inércia da Administração Pública e que a PGFN está capacitada para realizar suas novas atribuições”, sendo que muitas medidas já teriam sido adotadas visando a estruturação da PGFN para cumprir com as atribuições previstas pela Lei 11.457/07. Reconheceu que embora a PGFN careça de maior estrutura, 
a implementação das medidas estaria sujeita à disponibilidade orçamentária e limitações operacionais, "não se justificando a suspensão do disposto no art. 16, §1 ${ }^{\circ}$, da Lei n 11.457/07” (ADI 4.068, 2008, p. 590).

Quanto ao pedido de declaração de inconstitucionalidade circunstancial, o Advogado-Geral da União explicou inexistir vinculação entre o dispositivo impugnado e as condicionantes suscitadas pelo CFOAB que, ainda que existentes, "constituiria matéria infraconstitucional restrita à aplicabilidade da norma e não à sua eficácia constitucional, o que não poderia ser objeto de ação direta de inconstitucionalidade” (ADI 4.068, 2009, p. 592) [grifo do autor]. Por fim, o Advogado-Geral da União pugna pela improcedência da ação, ressaltando a impossibilidade de invocar precedentes do Supremo Tribunal Federal no HC 70.514 e nos RE 135.328 e 147.776 com vistas à declaração do dispositivo impugnado como “ainda inconstitucional”, uma vez que naqueles casos, diferentemente, verificou-se a existência de conflito entre a norma impugnada e a Constituição para, somente após, fazer as ponderações acerca da ausência ou precariedade das Defensorias Públicas.

O Procurador-Geral da República opinou pela improcedência da ação afirmando que ação busca questionar a atuação do Poder Executivo e não a lei, acrescentando que "uma condição de aplicabilidade de status constitucional não tem o condão de caracterizar a inconstitucionalidade de previsões legais que não a cumprem”. Ao final ressalta que inexiste relação entre o caso concreto tratado e as decisões proferidas pelo STF nas ações consideradas como paradigmas pelo Conselho requerente. Foi admitido como amicus curiae o Sindicato Nacional dos Procuradores da Fazenda Nacional - SINPROFAZ.

Ponderados os termos da Ação Direta de Inconstitucionalidade importa analisar a decisão do Supremo Tribunal Federal.

\subsection{Análise do julgado na ADI 4.068/DF}

Analisando o tema, a Relatora (Ministra Carmem Lúcia) proferiu voto pela improcedência do pedido expondo que a criação da Super-Receita representou "avanço na administração tributária concentrando essas atribuições em um só órgão e privilegiando a eficiência administrativa”. Asseverou, ainda, que a lei cujo dispositivo se discute a constitucionalidade assegurou à "Procuradoria da Fazenda Nacional condições mínimas de infraestrutura para lhe facilitar a absorção de suas novas atribuições e competências" (ADI, 2020, p. 4,5).

A decisão afirmou que o legislador buscou a eficiência na administração tributária ao concentrar na Procuradoria-Geral da Fazenda Nacional a atuação, a fiscalização e a cobrança também dos créditos de natureza previdenciária evidenciando que foram tomadas as medidas legislativas para atenuar os impactos da transição. Acrescentou que após mais de uma década da propositura da ação e, considerando as medidas que têm sido adotadas desde então, é de se concluir a existência de erro de avaliação administrativa pelo Conselho Federal da Ordem dos Advogados do Brasil.

A Relatora prossegue afirmando que não houve ofensa ao princípio da razoabilidade e, portanto, não caberia ao Poder Judiciário discutir o juízo de conveniência e oportunidade da Administração Pública de modo a não ferir o princípio da separação dos poderes finalizando seu voto pela improcedência do pedido o que foi acompanhado, por unanimidade, pelos demais julgadores. A decisão transitou em julgado em 02/09/2020.

Como se pode notar das manifestações do Advogado-Geral da União e do Procurador-Geral da República não apresentaram argumentos que refutassem especificamente a tese de inconstitucionalidade circunstancial com declaração de norma "ainda inconstitucional" construída pelo Conselho Federal da OAB.

De igual modo a decisão proferida na ação também não enfrentou a tese da inconstitucionalidade circunstancial, limitando-se decidir pela constitucionalidade do dispositivo impugnado, sem analisar a aplicação das teses já admitidas pelo Supremo Tribunal Federal em outras ações adotando o entendimento de que foram tomadas as medidas administrativas visando a estruturação da PGFN o que denota inexistência das circunstâncias fáticas subjacentes alegadas pelo Conselho Federal e, ainda, impossibilidade de discussão pelo Poder Judiciário do juízo de conveniência e oportunidade do administrador face a inexistência de ofensa ao princípio da razoabilidade. 


\section{Considerações Finais}

As circunstâncias excepcionais vivenciadas na atualidade em decorrência da pandemia de Covid-19 ganharam contornos especiais levando ao exame de decisões em situações de excepcionalidade temporária. Nesse contexto é que se evidenciou a relevância da análise da tese construída pelo Conselho Federal da Ordem dos Advogados do Brasil de inconstitucionalidade circunstancial apresentada na Ação Direita de Inconstitucionalidade n. 4.068/DF.

Embora a regra no ordenamento jurídico nacional quanto ao controle de constitucionalidade seja da nulidade, a jurisprudência do Supremo Tribunal Federal reconhece a necessidade de se modular os efeitos da declaração de inconstitucionalidade relativizando a teoria da nulidade. Assim, a Suprema Corte deveria, para além de retirar dos sistemas jurídicos normas inconstitucionais, preservar a legislação produzida cuja inconstitucionalidade seja momentânea superando-se, assim, o modelo binário entre constitucionalidade e inconstitucionalidade.

Inobstante as críticas quanto à aplicação da teoria no sistema de controle de constitucionalidade brasileiro, é certo que o Supremo Tribunal Federal deve restringir os efeitos da declaração de inconstitucionalidade adotando outras técnicas de interpretação consideradas intermediárias.

A tese proposta merecia análise quanto aos efeitos pretendidos e a legitimidade de se conferir ao STF a possibilidade de declarar a inconstitucionalidade de uma norma até que cessado o estado de excepcionalidade, pois o controle de constitucionalidade não comporta decisões com vigência temporária, pois inviável a repristinação uma lei após superação da situação de anormalidade.

Da análise da ADI n. 4.068 verificou-se que o Conselho Federal da Ordem dos Advogados do Brasil construiu uma nova tese cunhada de "inconstitucionalidade circunstancial" em que se buscava que o dispositivo impugnado fosse declarado circunstancialmente inconstitucional até que a Procuradoria-Geral da Fazenda Nacional- PGFN tivesse estrutura mínima necessária a realizar o encargo a que foi sujeitada pela lei, ou seja, a constitucionalidade da norma estaria condicionada à implementação de condições mínimas a autorizar a sua eficácia.

A decisão de improcedência do pedido assevera que a criação da Super-Receita representou progresso na administração tributária e que foram asseguradas pela lei medidas que atenuassem os impactos da transição, bem como as condições mínimas de infraestrutura a permitir que a Procuradoria-Geral da Fazenda Nacional absorvesse suas novas atribuições e competências. Ademais, considerou que não houve ofensa ao princípio da razoabilidade ressaltando que não é dado ao Poder Judiciário discutir o juízo de conveniência e oportunidade da Administração Pública, sob pena de violação ao princípio da separação dos poderes.

Infelizmente vislumbra-se que a tese apresentada pela PGFN acabou não sendo frontalmente enfrentada pelo Supremo Tribunal Federal e que a pretensão do CFOAB implicaria por invadir a discricionariedade do administrador para analisar a infraestrutura daquele órgão e sua compatibilidade com as condições e o prazo de aplicação da norma questionada, o que não seria possível.

\section{Referências}

Supremo Tribunal Federal (2008). Ação Direta de Inconstitucionalidade 4.068/DF. http://redir.stf.jus.br/estfvisualizadorpub/jsp/consultarproc essoeletronico/ConsultarProcessoEletronico.jsf?seqobjetoincidente=2610329.

Supremo Tribunal Federal (2020). Ação Direta de Inconstitucionalidade 4.068/DF. http://portal.stf.jus.br/processos/downloadPeca.asp?id $=15344140423 \&$ ext $=$.pdf.

Adeodato, J. M. (n.d.). Bases para uma metodologia da pesquisa em Direito. https://antigo.idp.edu.br/wpcontent/uploads/2018/04/bases_metodologia_direito_ADEODATO-1.pdf.

Barcellos, A. P. (2005). Ponderação, racionalidade e atividade jurisdicional. Rio de Janeiro: Renovar.

Bernardes, J. T. Normas Constitucionais ‘Circunstancialmente’ Inconstitucionais? https://www.emagis.com.br/area-gratuita/artigos/normas-constitucionaiscircunstancialmente-inconstitucionais-por-juliano-taveira-bernardes/. 
Research, Society and Development, v. 10, n. 3, e33410313424, 2021

(CC BY 4.0) | ISSN 2525-3409 | DOI: http://dx.doi.org/10.33448/rsd-v10i3.13424

Cervo, A. L., Bervian, P. A. (2002) Metodologia Científica. (5a ed.). Prentice Hall.

Chaves, C. F. B., \& Arcaro, A. A. (2020). Mutação constitucional entre a liminar e a decisão definitiva: o caso da adi no 2.415 e a norma ainda constitucional. Revista de Direito Público Contemporâneo, 1(2). 10.47096/rdpc.v1i2.97.

Coelho, E. S. (2014). Técnicas de decisão no controle de constitucionalidade, inconstitucionalidade circunstancial e a norma ainda inconstitucional. https://jus.com.br/artigos/33928/tecnicas-de-decisao-no-controle-deconstitucionalidade-inconstitucionalidade-circunstancial-e-a-norma-aindainconstitucional/3.

Ferreira, K. F. (2018). A atuação do Tribunal Constitucional Português no contexto de crise: a supremacia judicial em foco. [Dissertação de Mestrado, Universidade Federal de Juiz de Fora, Minas Gerais, Brasil]. https://repositorio.ufjf.br/jspui/handle/ufjf/7171.

Freire A., Frazão, C. E., Mudrovitsch, R. B., \& Rufino, V. S. O fenômeno da inconstitucionalidade circunstancial. https://www.jota.info/opiniao-eanalise/artigos/o-fenomeno-da-inconstitucionalidade-circunstancial-25042020.

Haberle, P. (2002) Hermenêutica Constitucional - A sociedade aberta dos intérpretes da Constituição, contribuição para a interpretação pluralista e a "procedimental” da Constituição. Porto Alegre: Sergio Antonio Fabris Editor.

Lei n. 11.457, de 16 de março de 2007. (2007). Dispõe sobre a Administração Tributária Federal; altera as Leis n.10.593, de 6 de dezembro de 2002, 10.683, de 28 de maio de 2003, 8.212, de 24 de julho de 1991, 10.910, de 15 de julho de 2004, o Decreto-Lei no 5.452, de $1^{\circ}$. de maio de 1943, e o Decreto no 70.235, de 6 de março de 1972; revoga dispositivos das Leis nos 8.212, de 24 de julho de 1991, 10.593, de 6 de dezembro de 2002, 10.910, de 15 de julho de 2004, 11.098, de 13 de janeiro de 2005, e 9.317, de 5 de dezembro de 1996; e dá outras providências. http://www.planalto.gov.br/ccivil_03/_ato20072010/2007/lei/111457.htm.

Mendes, G. F. (2020). Jurisprudência de Crise e Pensamento do Possível: caminhos constitucionais. https://www.conjur.com.br/2020-abr-11/observatorioconstitucional-jurisprudencia-crise-pensamento-possivel-caminhos-solucoes-constitucionais.

Nascimento, R. S. (2020). Existe uma inconstitucionalidade 'circunstancial'? https://www.jota.info/opiniao-e-analise/artigos/existe-uma-inconstitucionalidadecircunstancial-06052020.

Padilha, R. (2020). Direito Constitucional. (6a ed.). Forense, Método.

Pinheiro, A. S. (2014). A jurisprudência da crise: Tribunal Constitucional português (2011-2013). Observatório da Jurisdição Constitucional. Brasília: IDP, 7(1), 168-189. https://www.portaldeperiodicos.idp.edu.br/observatorio/article/view/961/641.

Sousa, R. V. O. (2020). A delicada função de julgar: as jurisprudências consolidadas e as jurisprudências da crise no cenário da pandemia. Revista Da Escola Judiciária do Piauí, 2(2). http://www.tjpi.jus.br/revistaejud/index.php/escolajudiciariapiaui/article/view/69. 